Special Issue of the 8th International Advances in Applied Physics and Materials Science Congress (APMAS 2018)

\title{
Effects of Potentiostatic Polarization during Slow Strain Rate Testing (SSRT) in Natural Seawater on the Fracture Behavior of High Strength Steel
}

\author{
J.H. LeE, K.H. Jung, S.J. KIM* \\ Mokpo National Maritime University, Division of Marine Engineering, Mokpo, Korea
}

\begin{abstract}
In the present study, a high strength steel for offshore wind turbine tower substructure was submitted to tensile load using slow strain rate technique to evaluate fracture characteristics of the steel with application of electrochemical potentials ranging from free corrosion potential to $-1.2 \mathrm{~V}$ in natural seawater. The results of the study revealed that the fracture characteristics of the steel changed drastically with different applied potentials. The failure time ratio was 0.5 or less in the potential range of $-1.0 \mathrm{~V}$ to $-1.20 \mathrm{~V}$ due to hydrogen evolution. The fractured surface after the slow strain rate test indicated that the brittle fracture tendency was prevalent in the potential region corresponding to the hydrogen embrittlement. It is concluded that cathodic overprotection exceeding $-1.2 \mathrm{~V}$ may lead to brittle fracture of the offshore steel structure.
\end{abstract}

DOI: 10.12693/APhysPolA.135.1023

PACS/topics: high strength steel, offshore, stress corrosion cracking, hydrogen embrittlement, seawater

\section{Introduction}

Corrosion is a major problem in offshore environments due to extreme operational conditions and the presence of corrosive medium, and therefore corrosion protection measures are essentially employed to protect the offshore substructure from aggressive corrosion attacks. Impressed current cathodic protection (ICCP) is considered as an effective method to protect the metallic structure against corrosive medium. In application of ICCP, optimization of protection potential is important because if the steel structure is cathodically over-protected, the structure becomes vulnerable to corrosion damage caused by cathodic disbonding or hydrogen embrittlement (also called hydrogen-assisted cracking) [1]. Therefore, optimization of protection potential is essential to select the best possible condition for corrosion protection. With increasing application of high strength grade steels in offshore structure, there is potentially a high risk of hydrogen embrittlement due to the cathodic protection. Many researches are found in the literature on hydrogen embrittlement of high strength steel [2-4]. They mainly focused on the hydrogen effects on hydrogen embrittlement of the steel. However, only a few studies deal with hydrogen-assisted cracking of high strength steel under the influence of externally applied electrochemical potential in chloride solution $[5,6]$.

In this study, S355ML steel specimens for offshore wind turbine tower substructure were exposed to various anodic and cathodic potentials under slow strain rate testing in natural seawater solution. In the slow strain rate test (SSRT), tensile loading at slow strain rate can induce

*corresponding author; e-mail: ksj@mmu.ac.kr localized hydrogen agglomeration through diffusion of hydrogen in the steel, which can lead to brittle fracture, enabling further evaluation of fracture behavior of the steel with different applied potentials.

\section{Experimental procedure}

The material used in this study was the S355ML steel which is a high-strength low-alloyed structural steel manufactured by thermo-mechanical control process (TMCP). The chemical composition of the steel is [wt\%]: C 0.14, Si 0.5, Mn 1.6, S 0.025, N 0.02, Al 0.02, Nb 0.05, $\mathrm{V} 0.1$, Ti 0.05 , Cr 0.30, Ni 0.50, Mo 0.10, Cu 0.55 and Fe balance. The tensile test specimen was machined so that it had the gauge length of $25 \mathrm{~mm}$ and the parallel length of $55 \mathrm{~mm}$. Figure 1 shows a three-electrode electrochemical cell configuration containing natural seawater solution attached to the SSRT machine. In the electrochemical cell, the working electrode was a tensile test specimen,

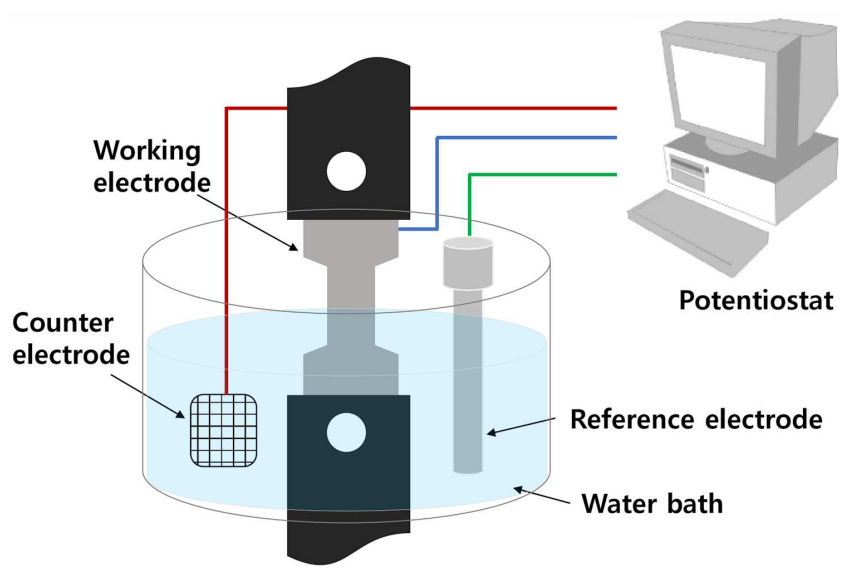

Fig. 1. Configuration of SSRT instrument equipped with electrode cell. 
the counter electrode was $\mathrm{Pt}$ mesh, and the reference electrode was silver-silver chloride electrode $(\mathrm{Ag} / \mathrm{AgCl})$. The electrochemical tensile test specimen was electrically insulated from the seawater solution with masking tape except for the parallel parts, and the surface area exposed to the solution was approximately $5.5 \mathrm{~cm}^{2}$. In the slow strain rate tensile test, the specimen immersed in the electrochemical corrosion cell containing the seawater solution at room temperature were exposed to various potentiostatic conditions ranging from $0 \mathrm{~V}$ (free corrosion potential) to $-1.2 \mathrm{~V}$ vs reference electrode. A tensile load was applied at a constant crosshead speed of $0.006 \mathrm{~mm} / \mathrm{min}$ until fracture in a tensile testing machine while applying a potential to the specimen, simultaneously. After the completion of each test, the specimen was washed with distilled water and acetone, dried in a hot air dryer, and stored in a vacuum dryer at $50{ }^{\circ} \mathrm{C}$ for microscopic examination. The fractured surfaces were observed with scanning electron microscope (SEM) and compared with each other by applied potentials.

\section{Results and discussion}

Figure 2 shows the change of current density of S355ML steel with time measured from the slow strain rate tensile test to the fracture with applying various potentials in natural seawater solution. Fig. 2 (a) shows the change of current density when applying potentials of $0 \div-0.60 \mathrm{~V}$, which is the potential region corresponding to the anodic polarization. The current density measured in this test was a value considering the initial surface area before the test, and did not reflect the change in surface area during loading. The potentials of $0 \mathrm{~V},-0.25 \mathrm{~V}$, and $-0.50 \mathrm{~V}$ showed a positive current density until fracture, which means that the anodic dissolution reaction proceeded to failure. At the potential of $-0.60 \mathrm{~V}$, the current density was lower than that of the previously applied potential, and the negative current density was maintained until the fracture even though it corresponds to anodic polarization on the polarization curve. This may be attributed to so-called "ennoblement" phenomenon in which the corrosion potential of the base material moves in the noble direction occurred by the tensile loading [7]. It is believed that the ennoblement is related to the increase of the electrical resistance of the specimen. The electrical resistance is proportional to the length of the conductor and inversely proportional to the cross-sectional area. In general, the electrical resistance at overall gauge length is increased by the elastic or plastic elongation of the specimen during loading. At this time, if the stress corrosion crack is initiated, the electric resistance is further increased due to the cross-sectional area reduced by the crack growth. This increase in electrical resistance is believed to be related to the ennoblement of corrosion potential. In other words, it is possible to monitor and detect stress corrosion cracking through measuring electrical resistance.
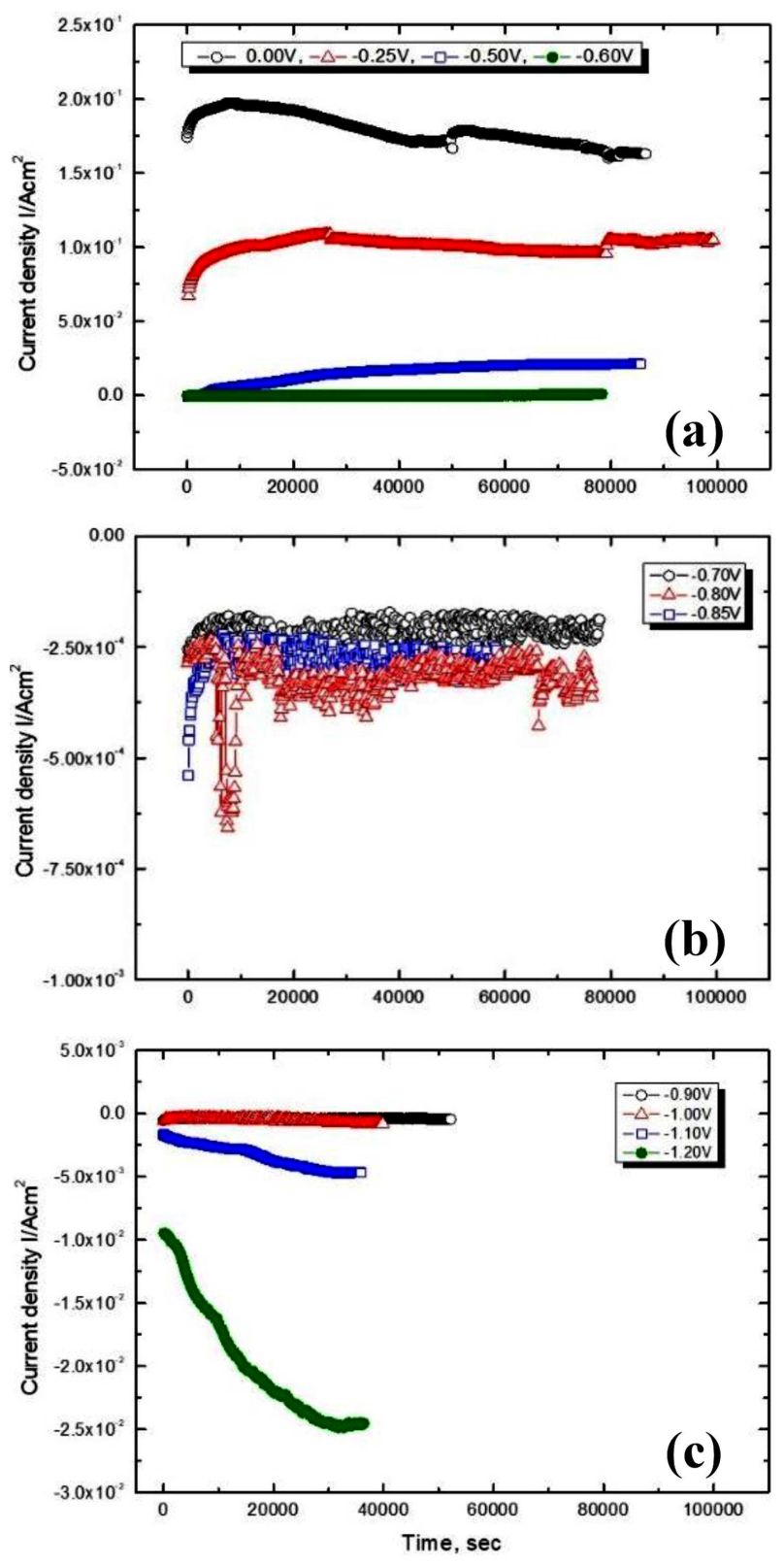

Fig. 2. Time-current density curves for S355ML steel at various applied potentials during SSRT in sea water.

Figure $2 \mathrm{~b}$ shows the change of current density applying potential of $-0.70 \mathrm{~V}$ which is close to the corrosion potential and $-0.80 \mathrm{~V}$ and $-0.85 \mathrm{~V}$ which correspond to the cathodic polarization. Overall, negative current densities were observed for the applied potentials to the fracture. At the potential of $-0.70 \mathrm{~V}$, it was expected to represent a positive current density value because it is a potential slightly nobler than the corrosion potential, but showed a negative current density value. Figure $2 \mathrm{c}$ shows the change in current density during applying potential of $-0.90 \mathrm{~V}$ to $-1.20 \mathrm{~V}$, corresponding to the cathodic polarization. It can be seen that as the applied potential shifted in the active direction, the magnitude of the current density became larger and the time to fracture was 
shortened. In addition, it was apparent that the current density tended to increase with time, especially for active applied potentials. At the applied potential of $-1.20 \mathrm{~V}$, which is the most active one among the applied potentials, initially the current density of $-9.4 \times 10^{-3} \mathrm{~A} / \mathrm{cm}^{2}$ was measured, but at the time of fracture the current density of $-2.4 \times 10^{-2} \mathrm{~A} / \mathrm{cm}^{2}$ was measured, showing a 2.5 -fold difference between the initial value and final value.

Evaluation method of susceptibility to stress corrosion cracking by slow strain rate test is described in ASTM G129. Typically, the susceptibility to stress corrosion cracking is expressed as the reduction rate of the crosssectional area, which is the value obtained by dividing the cross-sectional area change by the initial area. In the case of rod-shaped specimens, it is easy to calculate the area by measuring the diameters before and after the test. However, it is not easy to measure the crosssectional area of flat plate specimens, so other method was considered in this study.

The susceptibility to stress corrosion cracking can be measured by measuring the time to failure ratio (TFR) as shown in the following equation.

$$
\mathrm{TFR}=\frac{T F_{e}}{T F_{c}}
$$

$T F_{e}$ is the time from the test environment to the failure, and $T F_{c}$ is the time from the controlled environment to the failure. In this study, $T F_{e}$ corresponds to sea water or potential application condition, while $T F_{c}$ refers to atmospheric condition. A material with a failure time ratio in the range of 0.8 to 1.0 can be said to have high resistance to stress corrosion cracking and a value less than 0.5 can be said to be highly susceptible to stress corrosion cracking. Therefore, it is advantageous to maintain the failure time ratio close to 1 in order to improve resistance to stress corrosion cracking.

Figure 3 is a graph showing the stress-time curves of the S355ML steel during slow-strain rate test under atmospheric, seawater, and various potentiostatic conditions. At $0 \div-0.7 \mathrm{~V}$, which corresponds to the anodic polarization, the time to failure was found to be longer than the sea water condition $(18.05 \mathrm{~h})$. At $0 \mathrm{~V}$, the time to failure was similar to that of the atmospheric condition, and at $-0.25 \mathrm{~V}$ it was delayed rather than atmospheric condition. Even at $-0.50 \mathrm{~V}$ to $-0.70 \mathrm{~V}$, the time was slightly reduced, but it was longer than that in sea water condition. In the potential region corresponding to the anodic polarization, the time to fracture was shorter than that in the seawater condition in all the potential regions except for $-0.8 \mathrm{~V}$ and there was a tendency that the time was further shortened as the potential shifted in the active direction.

Figure 4 is the comparison of time-to-fracture by applied potentials, and the time-to-failure ratio was calculated and listed in Table I. The time-to-failure ratio was 0.74 in the seawater condition when the atmospheric
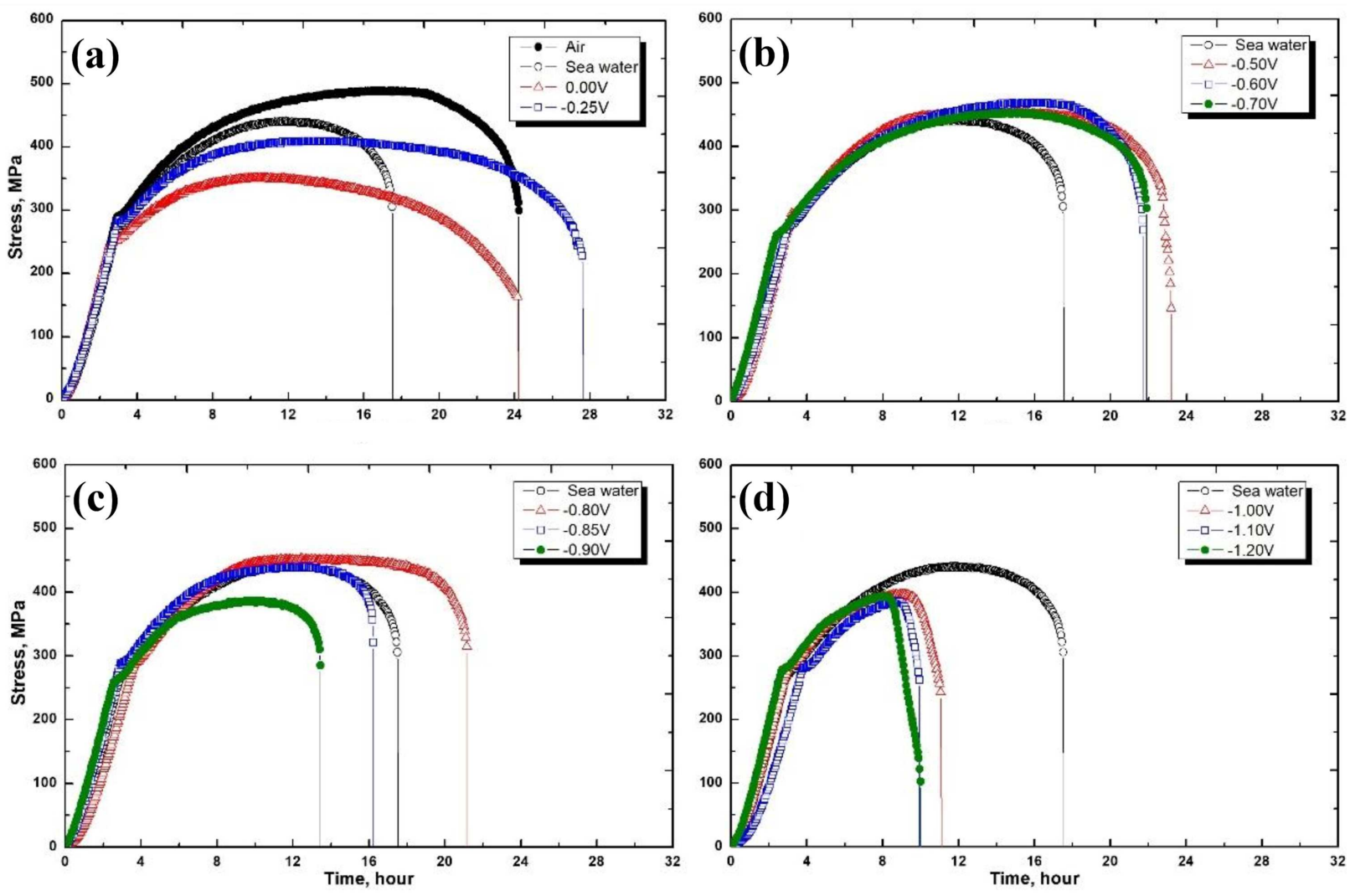

Fig. 3. Stress-time curves for S355ML steel tested with SSRT at applied potentials in sea water. 


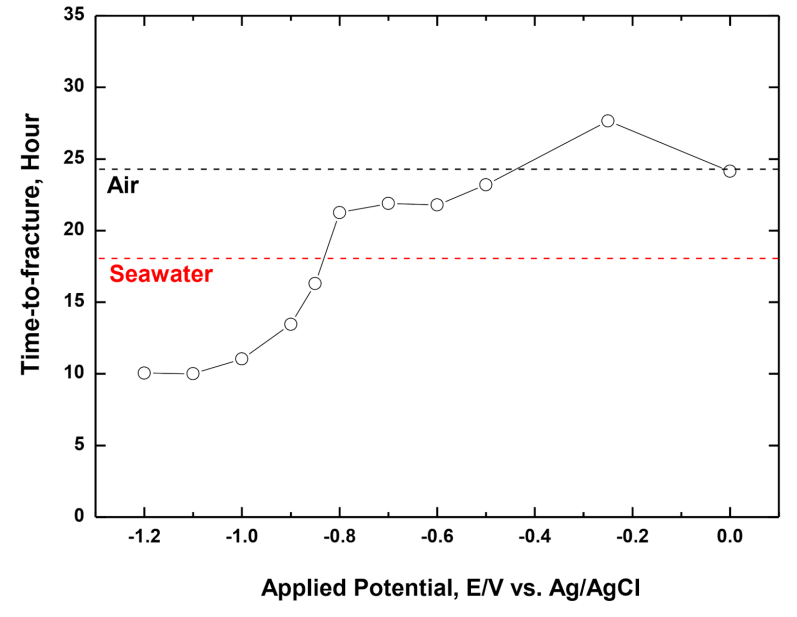

Fig. 4. Effect of applied potential on time-to-fracture for SSRT in sea water. condition was 1 , and it was found that the potential corresponding to the anodic polarization was 0.9 or more. In the case of the anodic polarization potential region $(0 \mathrm{~V}$ to $-0.70 \mathrm{~V})$, the resistance to stress corrosion cracking is considered to be high when the time-to-failure ratio is used as the criterion. However, this potential region is hardly regarded as the protection region, since the strength is small. A relatively high time-to-failure ratio, e.g. 0.88 was observed at $-0.85 \mathrm{~V}$, which corresponds to the cathodic polarization. Afterwards, the potential decreased sharply as it shifted in the active and then showed the lowest value of 0.41 at $-1.1 \mathrm{~V}$. The potential range of $-1.0 \mathrm{~V}$ to $-1.20 \mathrm{~V}$ corresponds to the activation polarization region due to hydrogen generation, and the time-to-failure ratio is 0.5 or less. Therefore, this potential range is considered to be vulnerable to stress corrosion cracking due to hydrogen embrittlement.

TABLE I

Time-to-fracture (time-to-failure ratio) as a function of applied potentials.

\begin{tabular}{c|c|c|c|c|c|c|c|c|c|c|c}
\hline \hline & $0 \mathrm{~V}$ & $-0.25 \mathrm{~V}$ & $-0.5 \mathrm{~V}$ & $-0.6 \mathrm{~V}$ & $-0.7 \mathrm{~V}$ & $-0.8 \mathrm{~V}$ & $-0.85 \mathrm{~V}$ & $-0.9 \mathrm{~V}$ & $-1.0 \mathrm{~V}$ & $-1.1 \mathrm{~V}$ & $-1.2 \mathrm{~V}$ \\
\hline $\begin{array}{c}\text { time to } \\
\text { failure } \\
{[\mathrm{H}]}\end{array}$ & 24.15 & 27.65 & 23.20 & 21.80 & 21.90 & 21.25 & 16.30 & 13.45 & 11.05 & 10.00 & 10.05 \\
\hline $\begin{array}{c}\text { time to } \\
\text { failure } \\
\text { ratio }\end{array}$ & 1 & 1.14 & 0.96 & 0.90 & 0.90 & 0.88 & 0.67 & 0.56 & 0.46 & 0.41 & 0.49 \\
\hline
\end{tabular}

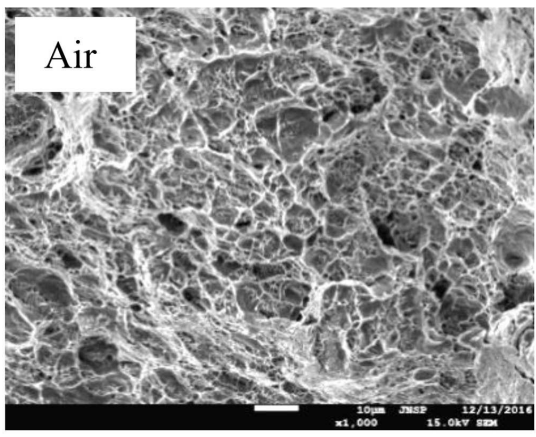

(a)

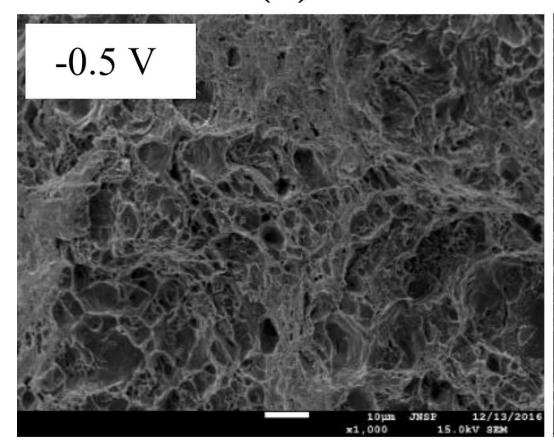

(d)

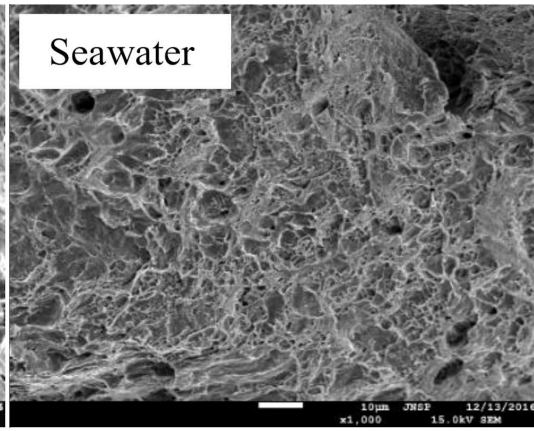

(b)

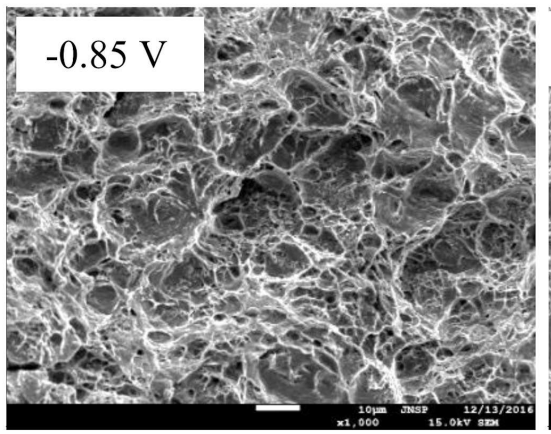

(e)

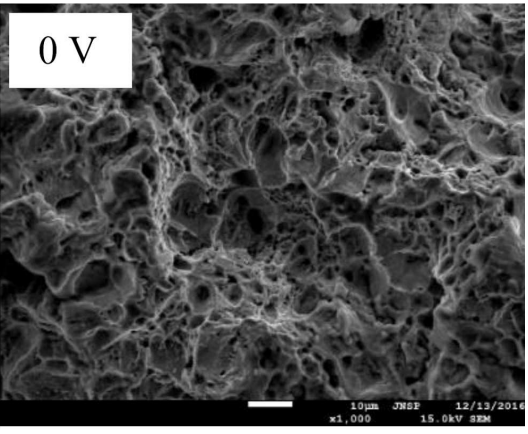

(c)

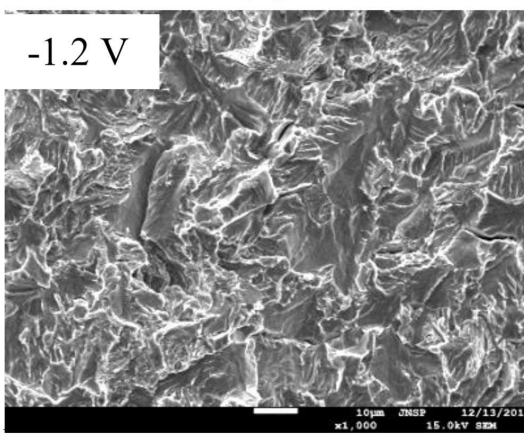

(f)

Fig. 5. Fractography of fractured surface of S355ML steel at various applied potentials in sea water. 
Figure 5 shows SEM photographs of fractured surface of S355ML steel after slow strain rate test under atmospheric, seawater, and various potentials $(0 \mathrm{~V},-0.5 \mathrm{~V}$, $-0.85 \mathrm{~V}$, and $-1.2 \mathrm{~V})$. In the atmospheric environment, a typical ductile fracture was observed with dimples composed of a microscopic crater shape. In the case of seawater condition, the ductile failure mode was observed, but the shape of the quasi - cleavage facet was partially observed. In the potential region of $0 \div-0.5 \mathrm{~V}$, the ductile fracture was dominant with the partial brittle fracture. In the case of $-0.85 \mathrm{~V}$, which corresponds to the cathodic polarization, the ductile fracture pattern predominated, and partially brittle fracture was present (Fig. $5 \mathrm{e})$. At the applied potential of $-1.2 \mathrm{~V}$, the failure mechanism no longer fully ductile but it turned into brittle with a beach mark pattern on the partly cleavage facet (Fig. 5f). This result was clearly distinguished from the seawater condition and the potential range above $-1.2 \mathrm{~V}$ indicating a mixed ductile and brittle facet. It is obvious that the potential of $-1.2 \mathrm{~V}$ was strongly affected by hydrogen because it falls into the activation polarization $\left(2 \mathrm{H}_{2} \mathrm{O}+2 e^{-} \rightarrow \mathrm{H}_{2}+2 \mathrm{OH}^{-}\right)$region by hydrogen evolution on the polarization curve. Such behavior can be attributed to the cathodic overprotection due to hydrogen embrittlement by a large amount of molecular hydrogen [8].

\section{Conclusion}

In this study, influences of anodic and cathodic potentials on the mechanical characteristics of S355ML steel specimens were investigated using slow strain rate loading in natural seawater solution. The result of the slow strain rate test showed different fracture characteristics depending on the applied potentials. The failure time ratio showing susceptibility to stress corrosion cracking was 0.5 or less in the potential range of $-1.0 \mathrm{~V}$ to $-1.20 \mathrm{~V}$ corresponding to the activation polarization region due to hydrogen evolution. The fractography after the slow strain rate test confirmed that the brittle fracture tendency was prevalent in the potential region corresponding to the hydrogen embrittlement. It is concluded that cathodic overprotection exceeding $1.2 \mathrm{~V}$ may lead to brittle fracture of the steel structure if conditions for hydrogen-assisted cracking are satisfied.

\section{Acknowledgments}

This paper presents the results of "Development of optimal corrosion management technology for offshore wind farm's structure" project by Korean Register, Institute of Energy Technology Evaluation and Planning (KETEP) grant funded by the Ministry of Trade, Industry \& Energy, Republic of Korea (project No. 20143010021820).

\section{References}

[1] T. Okstad, Ø. Rannestad, R. Johnsen, K. Nisancioglu, Corros. Sci. 63, 857 (2007).

[2] C. Batt, J. Dodson, M.J. Robinson, Br. Corros. J. 37, 194 (2002).

[3] M. Cabrini, S. Lorenzi, P. Marcassoli, T. Pastore, Corros. Rev. 29, 261 (2011).

[4] M. Wang, E. Akiyama, K. Tsuzaki, Corros. Sci. 49, 4081 (2007).

[5] S.J. Kim, S.K. Jang, I.I. Kim, Met. Mater. Int. 11, $63(2005)$.

[6] C. Batt, M.J. Robinson, Br. Corros. J. 37, 31 (2002).

[7] H. El Alami, J. Creus, X. Feaugas, Electrochim. Acta 51, 4716 (2006).

[8] D. Hardie, E.A. Charles, A.H. Lopez, Corros. Sci. 48, 4378 (2006). 